\title{
SISTEM MONITORING LEVEL AIR RADIATOR KENDARAAN DENGAN METODE FUZZY
}

\section{MONITORING LEVEL AIR RADIATOR VEHICLES SYSTEM WITH FUZZY METHOD}

\author{
Dina Hervita ${ }^{1}$, Ahmad Taqwa ${ }^{2}$, Martinus Mujur Rose ${ }^{3}$ \\ ${ }^{123}$ Jurusan Teknik Elektro, Program Studi Teknik Telekomunikasi DIV, Politeknik Negeri Sriwijaya \\ Jl. Srijaya Negara, Bukit Besar, Ilir Barat 1, Palembang, Sumatera Selatan \\ 1' dinnahervita@gmail.com, ${ }^{2}$ a_taqwa@yahoo.com, ${ }^{3}$ mujurrose@yahoo.com
}

\begin{abstract}
Abstrak
Hampir setiap kendaraan pasti perlu perawatan seperti ganti oli, ganti ban, air radiator, rem, bagian mesin dan masih banyak lagi. Namun, terkadang pemilik kendaraan kurang peduli dengan kondisi kendaraannya dan seringkali mengabaikan perawatan tersebut. Hal ini bisa berdampak buruk, bahkan bisa mengakibatkan kecelakaan. Oleh karna itu,sistem monitoring ini dirancang untuk memonitoring level air radiator pada tangki kendaraan. Sensor ultrasonik akan mengukur ketinggian air radiator pada tangki reservoil. Jika level air radiator pada tangki rendah maka pompa secara otomatis akan mengisi ulang air radiator dan buzzer akan berbunyi lebih cepat. Data dari sensor ultrasonik akan dikirim ke mikrokontroler dengan logika fuzzy. Pemilik kendaraan dapat mengakses informasi berupa ketinggian level air radiator di dalam tangki melalui modul wifi Wemos ESP8266 sehingga keadaan bagian dalam pada kendaraan dapat dimonitroing dan diatasi dengan cepat, mudah, dan efisien.
\end{abstract}

\section{Kata kunci: Metode Fuzzy, Mikrokontroller Atmega328, Modul Wemos ESP8266,} Radiator, Sensor Ultrasonik HC-SR04.

\begin{abstract}
Almost every vehicle will need maintenance such as oil change, tire change, water radiator, brake, engine parts and much more. However, sometimes vehicle owners are less concerned with the condition of the vehicle and often ignore the treatment. This can be bad, it can even lead to an accident. Therefore, the monitoring system is designed to monitor the level of radiator water in vehicle tanks. The ultrasonic sensor will measure the water level of the radiator in the reservoir tank. If the water level of the radiator in the tank is low then the pump will automatically recharge the radiator water and the buzzer will sound faster. The data from the ultrasonic sensor will be sent to the microcontroller with fuzzy logic. Vehicle owners can access information in the form of water level radiator in the tank via wifi module and wifi router. So the problem of damage to the vehicle can be overcome quickly, easily, and efficiently.
\end{abstract}

Keywords: Fuzzy Method, Microcontroller Atmega328, Wemos ESP8266 Module, Radiator, Ultrasonic Sensor HC-SR04.

\section{PENDAHULUAN}

Perkembangan teknologi yang semakin pesat telah membawa banyak pengaruh dalam berbagai aspek kehidupan terutama dibidang transportasi. Sekitar 15\% faktor kecelakaan lalu lintas disebabkan oleh kondisi fisik kendaraan seperti rem blong, pecah ban, kebocoran pada tangki, mesin terbakar dan lain-lain. Hal ini dikarenakan pemilik kendaraan kurang peduli dengan kesehatan kendaraannya atau lalai dalam mendeteksi adanya permasalahan di kendaraannya, sehingga seringkali mengabaikan untuk service kendaraan mereka sendiri secara rutin. 
Sistem kendali Fuzzy merupakan salah satu alternatif sistem kendali yang sederhana, dimana pada sistem kendali Fuzzy tidak memerlukan pengetahuan tentang parameter- parameter dari sistem. Sinyal kontrol diperoleh dari error (kesalahan) yaitu perbedaan antara keluaran terhadap keluaran dari sistem, selain itu terdapat pula masukan yang berupa perubahan error sistem yang merupakan selisih antara error sekarang dengan error sebelumnya.

Untuk mengurangi tingkat kecelakaan, dalam penelitian ini dirancang suatu sistem monitoring level air radiator dengan menggunakan mikrokontroler ATmega328 sebagai kontroler, dan logika Fuzzy sebagai metode pengendali. Keluaran dari kendali logika Fuzzy akan mengatur posisi tangki cadangan untuk mengisi air radiator tambahan, sehingga level cairan dalam tangki dapat dikendalikan.

\section{DASAR TEORI}

\subsection{Radiator}

Radiator adalah alat penukar panas yang digunakan untuk memindahkan energi panas dari satu media ke media lainnya yang tujuannya untuk mendinginkan maupun memanaskan dengan media berupa air.

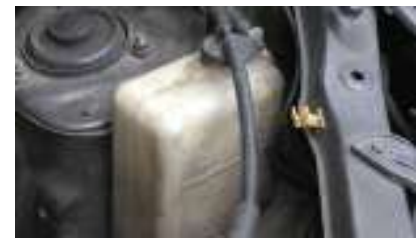

Gambar 1 Reservoir tank atau tangki cadangan

\subsection{Mikrokontroler ATmega328}

Mikrokontroler adalah sebuah sistem komputer fungsional dalam sebuah chip. Di dalamnya terkandung sebuah inti prosesor, memori (sejumlah kecil RAM, memori program, atau keduanya), dan perlengkapan input output.

\subsection{Sensor Ultrasonik}

Sensor adalah peralatan yang digunakan untuk merubah suatu besaran fisik menjadi besaran listrik sehingga dapat dianalisa dengan rangkain listrik tertentu. Sensor ultrasonik adalah sensor yang bekerja berdasarkan prinsip pantulan gelombang suara dan digunakan untuk mendeteksi keberadaan suatu objek tertentu di depannya, frekuensi kerjanya pada daerah di atas gelombang suara dari $40 \mathrm{KHz}$ hingga $400 \mathrm{KHz}$. Dalam penelitian ini menggunakan sensor HCSR04 yang merupakan sensor ultrasonik yang dapat digunakan untuk mengukur jarak antara penghalang dan sensor.

\section{$2.4 \quad$ Buzzer}

Buzzer adalah sebuah komponen elektronika yang berfungsi untuk mengubah getaran listrik menjadi getaran suara. Buzzer biasa digunakan sebagai indikator bahwa proses telah selesai atau terjadi suatu kesalahan pada sebuah alat (alarm). Dalam penelitian ini menggunakan Buzzer yang berjenis Piezoelectric. Buzzer dapat bekerja dengan baik dalam menghasilkan frekuensi di kisaran $1-5 \mathrm{kHz}$ hingga $100 \mathrm{kHz}$ untuk aplikasi Ultrasound. Tegangan Operasional Piezoelectric Buzzer yang umum biasanya berkisar diantara 3 Volt - 12 Volt.

\subsection{Pompa Sentrifugal}

Pompa Sentrifugal atau centrifugal pumps adalah pompa yang mempunyai elemen utama yakni berupa motor penggerak dengan sudu impeller yang berbutar dengan kecepatan tinggi. 


\subsection{Motor DC}

Motor DC merupakan peralatan elektromekanik dasar yang berfungsi untuk mengubah tenaga listrik menjadi tenaga mekanik. Driver motor L298N merupakan driver motor yang paling populer digunakan untuk mengontrol atau mengendalikan kecepatan dan arah pergerakan motor terutama untuk motor DC. Kelebihan akan modul driver motor L298N ini yaitu dalam hal kepresisian dalam mengontrol motor sehingga motor lebih mudah untuk dikontrol.

\subsection{Modul Wemos ESP8266}

Mikrokontroller Wemos adalah sebuah mikrokontroller pengembangan berbasis modul mikrokontroller ESP8266. Mikrokontroller wemos ini memiliki kemampuan untuk menyedikan fasilitas konektifitas WiFi dengan mudah serta memory yang digunakan sangat besar 4MB.

\section{METODOLOGI PENELITIAN}

\subsection{Perancangan Perangkat Keras ( Hardware)}

Perancangan perangkat keras (Hardware) yaitu alat yang akan di buat diawali dengan pembuatan diagram blok sistem secara keseluruhan. Diagram blok sistem secara keseluruhan ditunjukkan dalam Gambar sebagai berikut:

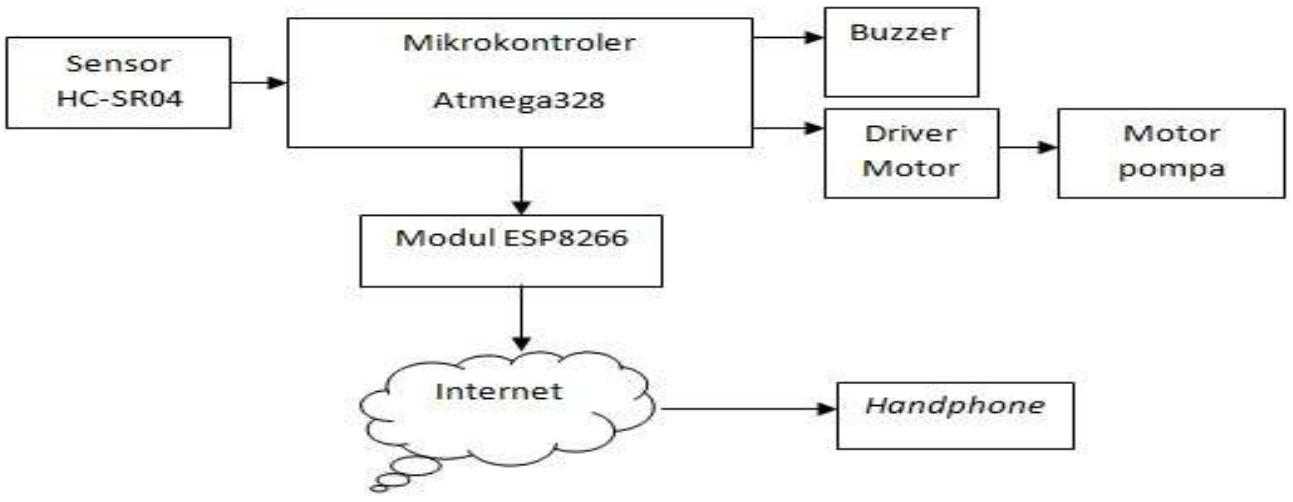

Gambar 2 Blok Diagram Sistem

Perangkat ini terdiri dari sensor ultrasonik HC-SR04 modul Arduino Atmega328, Modul Wifi ESP8266, dan laptop. ultrasonik HC-SR04 berfungsi memberikan informasi real-time pada arduino mengenai kondisi level air radiator dalam tangki melalui port serial COM. Arduino mengolah data yang dapat ditampilkan di laptop. 


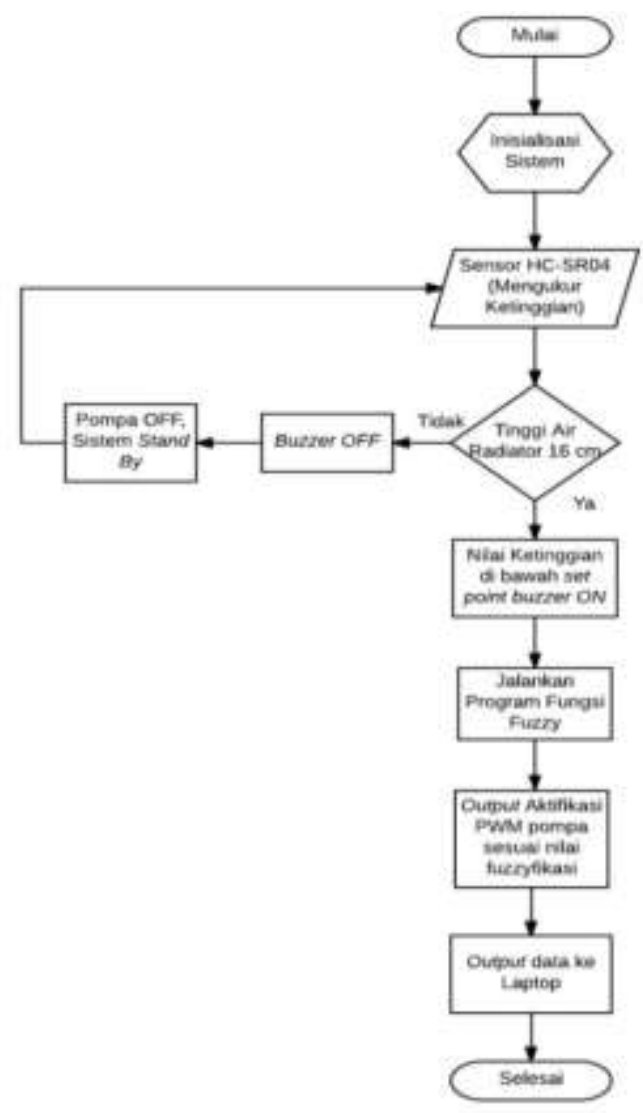

Gambar 3 Flowchart Sistem Keseluruhan

Sistem ini dirancang untuk memonitoring level air radiator pada tangki kendaraan berdasarkan sensor ultrasonik yang digunakan. Sistem ini akan mulai beroperasi ketika diberikan sumber tegangan melalui power supply. Program diawali dengan mulai yang berarti rangkaian dihidupkan, Program melakukan inisialisasi awal yang terhubung ke rangkaian sensor ultrasonik. Sensor ultrasonik sebagai pengendali ketinggian air radiator. Mikrokontroler akan mengambil data yang dikirimkan oleh sensor ultrasonik kemudian membandingkannya dengan nilai yang benar dan mengendalikan pengisian tangki. Ketinggian air radiator dalam tangki $16 \mathrm{~cm}$. Jika air radiator tidak mencapai ketinggian $16 \mathrm{~cm}$ dan berada pada level rendah sekitar $4 \mathrm{~cm}$ maka buzzer akan $O N$ dan pompa akan menghisap air radiator yang ada di tangki cadangan sebelahnya yang kemudian otomatis akan mengisi ulang ke tangki tersebut.

\subsection{Perancangan Perangkat Lunak (Software)}

Perancangan software memegang peranan penting dalam hal perhitungan dan pengolahan matematis dari keseluruhan program. Inti dari perancangan software ini yaitu perancangan algoritma Fuzzy. Struktur dasar pengendali logika Fuzzy ada 4 bagian yaitu fuzzifikasi, basis pengetahuan, logika pengambilan keputusan, dan defuzzifikasi.

Perancangan perangkat lunak pada sistem monitoring ini meliputi komunikasi serial, perancangan program pengukuran level ketinggian air radiator dan perancangan program algoritma logika Fuzzy. Perancangan program algoritma logika Fuzzy dan program monitoring menggunakan program arduino yang diproses menggunakan laptop, komunikasi serial dan pengaktifan sensor menggunakan bahasa $\mathrm{C}$ yang disimpan di dalam mikrokontroler ATmega832. 


\section{Fuzzifikasi}

Perancangan kendali logika fuzzy digunakan sebagai pengendali untuk mengendalikan level ketinggian air. Fuzzifikasi merupakan suatu proses untuk mengubah suatu input dari bentuk nilai pasti (crisp input) menjadi Fuzzy input (variabel linguistik) yang biasa disajikan dalam bentuk himpunan-himpunan Fuzzy dengan suatu fungsi keanggotaannya masing-masing.

Sistem ini memerlukan satu input yaitu sensor jarak ketinggian level air radiator. Pertama, sensor jarak ketinggian level air radiator dibaca oleh mikrokontroler, lalu dibentuk pernyataan linguistiknya. Pembentukan variabel linguistik yang ditunjukkan pada Tabel 1 yaitu :

Tabel 1 Input Sensor Jarak

\begin{tabular}{|c|c|}
\hline Sensor Ultrasonik & Variabel Linguistik \\
\hline $16 \mathrm{~cm}$ & Tinggi \\
\hline $12 \mathrm{~cm}$ & Sedang \\
\hline $8 \mathrm{~cm}$ & Rendah \\
\hline $4 \mathrm{~cm}$ & Sangat Rendah \\
\hline
\end{tabular}

Berdasarkan Tabel 1 diatas, maka grafik yang menunjukkan hubungan dari keempat variabel linguistik dapat dilihat pada Gambar 4.

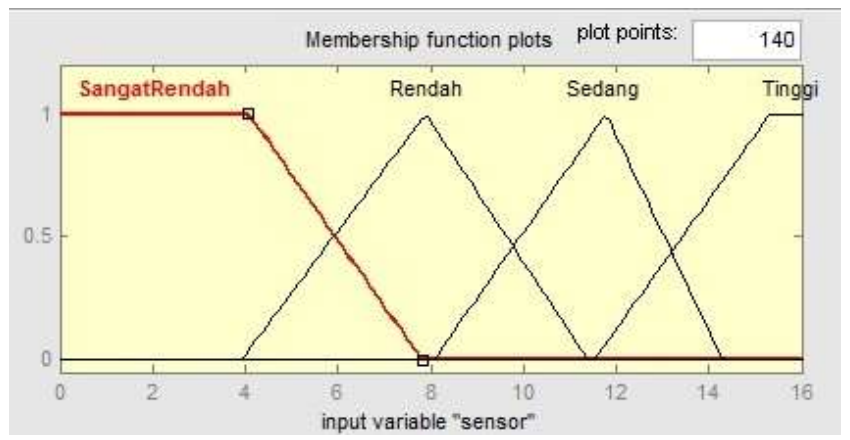

Gambar 4 Fungsi Keanggotaan Variabel Sensor

Jika keluaran motor pompa adalah sebesar 255, maka fuzzifikasi menghasilkan nilai linguistik cepat, medium dengan derajat keanggotaan 200, lambat dengan derajat keanggotaan 150 dan sangat lambat dengan derajat keanggotaan 100. Dapat dilihat pada tabel 2 dibawah ini:

Tabel 2 Output PWM Motor Pompa

\begin{tabular}{|c|c|}
\hline Pompa & Variabel Linguistik \\
\hline 100 & Sangat Lambat \\
\hline 150 & Lambat \\
\hline 200 & Sedang \\
\hline 255 & Cepat \\
\hline
\end{tabular}

Berdasarkan Tabel 2 diatas, maka grafik yang menunjukkan hubungan kecepatan motor pompa dari keempat variabel linguistik dapat dilihat pada Gambar 5. 


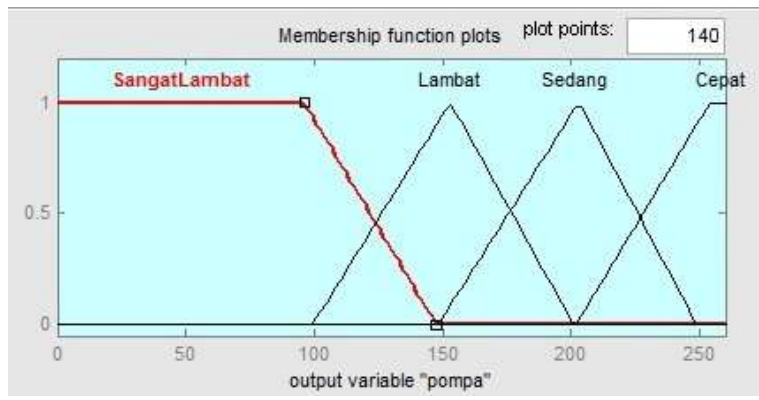

Gambar 5. Fungsi Keanggotaan Variabel Pompa

\section{Basis Pengetahuan}

Basis pengetahuan berisi pengetahuan system kendali sebagai pedoman evaluasi keadaan sistem untuk mendapatkan keluaran kendali sesuai yang diinginkan oleh perancang. Basis pengetahuan terdiri dari basis data dan basis aturan Fuzzy.

Basis data mencakup perancangan fungsi keanggotaan untuk variabel masukan dan keluaran, pendefinisian semesta pembicaraan dan penentuan variabel linguistik setiap variabel masukan dan keluaran.

Basis aturan kendali Fuzzy digunakan untuk menghubungkan variabel-variabel masukan dan variabel-variabel keluaran. Basis aturan Fuzzy merupakan kumpulan pernyataan aturan 'JIKAMAKA' atau ' $I F-T H E N$ ' yang didasarkan pada pengetahuan manusia untuk mengolah variabel masukan sehingga menghasilkan variabel keluaran dalam bentuk himpunan Fuzzy.

\section{Logika Pengambilan Keputusan}

Pengambilan keputusan dengan metode Sugeno dilakukan setelah proses fuzifikasi yang diolah berdasarkan basis aturan yang telah dibuat. Langkah selanjutnya, kedua masukan diproses dengan operator AND yang akan mengambil nilai paling minimal dari keduanya. Implikasi MIN akan memotong derajat keanggotaaan variabel keluaran pada nilai keluaran setelah melalui operator AND. Setelah semua aturan Fuzzy dieksekusi, dilakukan proses agregasi dengan mengambil nilai maksimal dari masing-masing fungsi keanggotaan variabel keluaran. Proses pengambilan keputusan dengan metode Sugeno ditunjukkan dalam Gambar 3.

\section{Defuzzifikasi}

Defuzzifikasi adalah proses pengubahan besaran Fuzzy yang disajikan dalam himpunan Fuzzy ke sinyal yang berbentuk crisp. Metode defuzzifikasi yang digunakan adalah metode ratarata terbobot (weighted average). Pada metode rata-rata terbobot, nilai keluaran tegas diperoleh dari jumlah hasil kali keluaran Fuzzy untuk setiap himpunan Fuzzy keluaran dengan nilai parameter pada sumbu z dibagi dengan jumlah keluaran Fuzzy untuk setiap himpunan Fuzzy keluaran. Rumus metode defuzzifikasi rata-rata terbobot adalah sebagai berikut :

Keluaran Crisp $=\frac{\sum(\text { Keluaran Fuzzy }) \mathrm{x}(\text { Nilai Parameter Pada Sumbu z })}{\sum(\text { Keluaran Fuzzy })}$

Keluaran pada proes defuzzifikasi merupakan hasil dari proses kendali fuzzy secara keseluruhan. Keluaran ini berupa himpunan crisp yang akan mengendalikan sistem yang dikontrol. 


\section{HASIL DAN PEMBAHASAN \\ 4.1 Hasil Perhitungan Fuzzy}

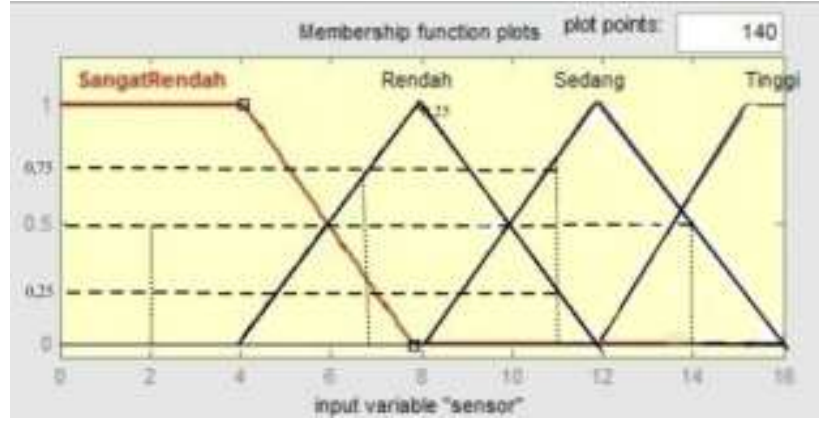

Gambar 6. Fungsi Keanggotaan Variabel Sensor

Level $1=14 \mathrm{~cm}$, Level $2=10 \mathrm{~cm}$, Level $3=6 \mathrm{~cm}$, Level $4=2 \mathrm{~cm}$

$\mu$ Sangat Rendah [2] $=\frac{(x-0)}{(4-0)}=\frac{(2-0)}{(4-0)}=0,5$

$$
=\frac{(4-x)}{(4-0)}=\frac{(4-2)}{(4-0)}=0,5
$$

$\mu$ Rendah [7] $=\frac{(x-4)}{(8-4)}=\frac{(7-4)}{(8-4)}=0,75$

$$
=\frac{(x-7)}{(8-4)}=\frac{(8-7)}{(8-4)}=0,5
$$

$\mu$ Sedang $[11]=\frac{(x-8)}{(12-8)}=\frac{(11-8)}{(12-8)}=0,75$

$$
=\frac{(12-x)}{(12-8)}=\frac{(12-11)}{(12-8)}=0,25
$$

$\mu$ Tinggi $[14]=\frac{(x-12)}{(16-12)}=\frac{(14-12)}{(16-12)}=0,5$

$$
=\frac{(16-x)}{(16-12)}=\frac{(16-14)}{(16-12)}=0,5
$$

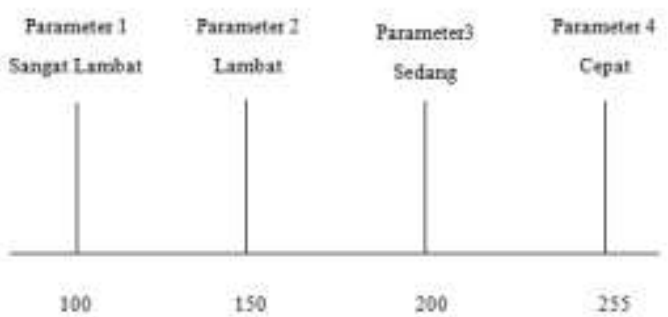

Gambar 7. Nilai PWM Kecepatan Motor Pompa

Masukan kemudian diolah dengan diawali mulai dari fuzzifikasi hingga defuzzifikasi. Pada penelitian ini juga menggunakan aturan dasar yang sudah dirancang.

Tabel 3. Aturan Dasar Fuzzy

\begin{tabular}{|c|c|c|c|c|}
\hline \multirow{2}{*}{ IF - THEN } & \multicolumn{4}{|c|}{ Pengisian Pompa } \\
\cline { 2 - 5 } & Cepat & Sedang & Lambat & Sangat Lambat \\
\hline Sangat Rendah & Bahaya & Waspada & Aman & Aman \\
\hline Rendah & Bahaya & Waspada & Aman & Aman \\
\hline Sedang & Waspada & Waspada & Aman & Aman \\
\hline Tinggi & Aman & Aman & Aman & Aman \\
\hline
\end{tabular}


Aturan dasar fuzzy diproses menggunakan fungsi implikasi MIN yang mengambil nilai minimal dari nilai masukan. Tahap selanjutnya yaitu defuzzifikasi, untuk mengubah nilai keluaran berupa data crisp dengan menggunakan nilai rata-rata (weighted average).

Keluaran Crisp $=\frac{\sum(\text { Keluaran Fuzzy) } \mathrm{x}(\text { Nilai Parameter Pada Sumbu z) }}{\sum \text { (Keluaran Fuzzy) }}$

$$
=\frac{(0,25 \times 100)+(0,5 \times 250)}{0,25+0,5}=200
$$

\subsection{Hasil Pengujian Sensor Ultrasonik}

Pengujian dilakukan dengan cara menghubungkan sensor ultrasonik dengan sistem minimum yang telah diberikan program pembacaan sensor ultrasonik dengan mengeluarkan data jarak di komputer untuk melakukkan pengecekan data jarak yang dibaca oleh sensor. Sensor ultrasonik diletakan di atas tangki, pengukuran dilakukan dengan membandingkan nilai keluaran dari sensor dengan hasil pengukuran menggunakan penggaris. Kemudian akan dilakukan analisis keakuarasian sensor dari hasil pengukuran didapatkan. Tabel 1 merupakan perbandingan jarak hasil pembacaan dari sensor dan pengukuruan dengan penggaris.

Tabel 4. Pengujian Perbandingan Jarak Sensor dengan Jarak Sebenarnya

\begin{tabular}{|c|c|c|c|c|c|}
\hline $\begin{array}{c}\text { Level } \\
\text { Ketinggian } \\
\text { Air Radiator }\end{array}$ & $\begin{array}{c}\text { Data } \\
\text { Pengujian }\end{array}$ & $\begin{array}{c}\text { Ketinggian } \\
\text { Air } \\
\text { Radiator } \\
(\mathrm{cm})\end{array}$ & $\begin{array}{c}\text { Alat } \\
\text { Ukur } \\
(\mathrm{cm})\end{array}$ & $\begin{array}{c}\text { Kapasitas } \\
\text { Air Radiator } \\
(\ell)\end{array}$ & Buzzer \\
\hline \multirow{4}{*}{ Tinggi } & Data 1 & 15,83 & 16 & 1,92 & OFF \\
\cline { 2 - 6 } & Data 2 & 14,17 & 15 & 1,55 & OFF \\
\cline { 2 - 6 } & Data 3 & 13,64 & 14,5 & 1,55 & OFF \\
\hline \multirow{4}{*}{ Sedang } & Data 1 & 12,72 & 12 & 1.53 & OFF \\
\cline { 2 - 6 } & Data 2 & 11,28 & 11 & 1,30 & OFF \\
\cline { 2 - 6 } & Data 3 & 10,26 & 10 & 1,8 & OFF \\
\hline \multirow{4}{*}{ Rendah } & Data 1 & 8,79 & 8 & 1.5 & OFF \\
\cline { 2 - 6 } & Data 2 & 7,55 & 7,2 & 0,90 & OFF \\
\cline { 2 - 6 } & Data 3 & 6,17 & 6,4 & 0,81 & OFF \\
\hline \multirow{2}{*}{$\begin{array}{c}\text { Sangat } \\
\text { Rendah }\end{array}$} & Data 1 & 4,38 & 4 & 0,59 & ON \\
\cline { 2 - 6 } & Data 2 & 3,05 & 3,1 & 0,40 & ON \\
\cline { 2 - 6 } & Data 3 & 2,24 & 2 & 0,21 & ON \\
\hline
\end{tabular}

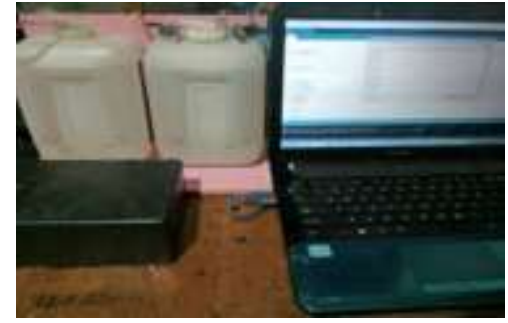

Gambar 8 Pengujian Sensor Ultrasonik Pada Tangki Cadangan

Terlihat perbandingan jarak yang terukur oleh sensor dan penggaris tidak berbeda jauh hanya selisih $1 \mathrm{~cm}$. Tetapi pada saat benda berada pada jarak lebih dari $16 \mathrm{~cm}$ mulai 
menunjukkan hasil yang kurang presisi, hal ini dikarenakan keterbatasan sensor. Namun ini tidak terlalu berpengaruh terhadap kinerja sistem. Hanya saja jarak yang terukur sensor dengan sebenarnya kurang akurat yaitu maksimum $1 \mathrm{~cm}$.

\subsection{Hasil Pengujian Motor Pompa}

Pengujian sensor ultrasonik dilakukan untuk mengetahui apakah sensor bekerja dengan baik. Dimana jarak yang terbaca oleh sensor mendekati hasil pengukuran secara manual menggunakan penggaris. Pengujian dilakukan dengan cara menghubungkan sensor ultrasonik dengan sistem minimum yang telah diberikan program pembacaan sensor ultrasonik dengan mengeluarkan data jarak di komputer untuk melakukkan pengecekan data jarak yang dibaca oleh sensor. Sensor diletakan di dalam tangki, pengukuran dilakukan dengan membandingkan nilai keluaran dari sensor dengan hasil pengukuran menggunakan penggaris. Kemudian akan dilakukan analisis keakuarasian sensor dari hasil pengukuran didapatkan. Tabel 1 merupakan perbandingan jarak hasil pembacaan dari sensor dan pengukuruan dengan penggaris.

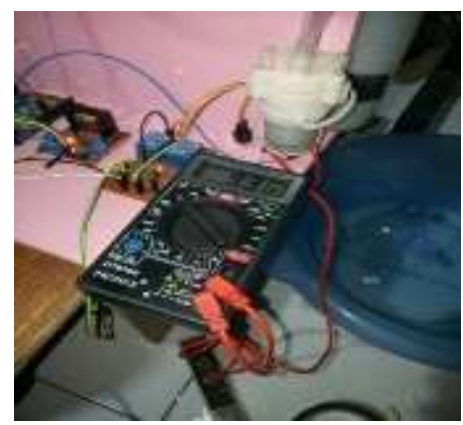

Gambar 9. Pengukuran Tegangan Pompa Dengan Multimeter

Tabel 4 Perhitungan Tegangan Motor Pompa Saat Mengisi Tangki

\begin{tabular}{|c|c|c|c|c|c|}
\hline No & $\begin{array}{c}\text { Range Sensor } \\
\text { Ultrasonik }(\mathrm{cm})\end{array}$ & $\begin{array}{c}\text { Tegangan Catu } \\
\text { Daya (V) }\end{array}$ & $\begin{array}{c}\text { Tegangan Motor } \\
\text { Pompa (V) }\end{array}$ & $\begin{array}{c}\text { Waktu } \\
\text { Pengisian }\end{array}$ & Keterangan \\
\hline 1 & $0-4$ & $12 \mathrm{~V}$ & 9,04 & - & Cepat \\
\hline 2 & $4-8$ & $12 \mathrm{~V}$ & 7,59 & $30,56 \mathrm{~s}$ & Sedang \\
\hline 3 & $8-12$ & $12 \mathrm{~V}$ & 6,75 & $38,89 \mathrm{~s}$ & Lambat \\
\hline 4 & $12-16$ & $12 \mathrm{~V}$ & 5,98 & $\begin{array}{c}\text { Lebih dari 3 } \\
\text { menit }\end{array}$ & Sangat Lambat \\
\hline
\end{tabular}

\section{KESIMPULAN DAN SARAN}

\subsection{KESIMPULAN}

Dari hasil pengujian dan analisis yang telah dilakukan pada perancangan sistem monitoring ketinggian level air radiator menggunakan metode logika fuzzy dapat disimpulkan bahwa:

1. Posisi awal level ketinggian air radiator di dalam tangki cadangan berada pada $16 \mathrm{~cm}$ dengan kondisi kapasitas air radiator penuh.

2. Ketika kendaraan berjalan setiap hari maka kapasitas air radiator menurun beberapa centimeter, maka otomatis pompa akan mengisi ke dalam tangki.

3. Pengukuran respon sistem level ketinggian air radiator pada motor pompa berdasarkan kondisi sensor, semakin rendah level air radiator maka semakin besar tegangan yang dihasilkan dan waktu yang dibutuhkan cukup singkat hanya 30,56 second untuk mengisi tangki. Sebaliknya, semakin tinggi level air yang akan diisi maka semakin kecil tegangan yang dihasilkan dan waktu yang dibutuhkan cukup lama sekitar lebih dari 5 menit 


\subsection{SARAN}

Saran untuk penelitian lebih lanjut dapat ditambahkan mengenai sistem monitoring tidak hanya pada bagian tangki radiator saja, tetapi pada bagian ban, rem, mesin, dan sebagainya.

\section{DAFTAR PUSTAKA}

[1] Cucun Wida.2012. Implementasi Fuzzy Logic Controller Untuk Pengendalian Level Air. Politeknik Negeri Bandung.

[2] Harapan Lismanto Gratianus, dkk.2013. Perancangan Kendali Valve Dan Pemantauan Pendistribusian Cairan Pada Tangki. Universitas Telkom: Bandung.

[3] Agus Margiantono dan Andi Kurniawan Nugroho.2013. Pengendalian Tinggi Permukaan Cairan Berbasis Fuzzy. Universitas Negeri Semarang

[4] Ilfan Arifin.2015. Automatic Water Level Control Berbasis Mikrocontroller Dengan Sensor Ultrasonik. Universitas Negeri Semarang.

[5] Gigih Prio Nugroho dkk.2013. Sistem Pendeteksi Dini Banjir Menggunakan Sensor Kecepatan Air dan Sensor Ketinggian Air Pada Mikrokontroler Arduino. Institut Teknologi Sepuluh November. Surabaya.

[6] Edwaw Yazid.2009. Penerapan Kendali Cerdas Pada Sistem Tangki Air Menggunakan Logika Fuzzy. Lembaga Ilmu Pengetahuan Indonesia. Bandung.

[7] Setiawan Ari Wibowo.2009. Pengendalian Level Ketinggian Air Dengan Menggunakan Logika Fuzzy. Universitas Komputer Indonesia: Bandung.

[8] Irfiani Ayu Dita.2016. Rancang Bangun Alat Pengukur Level Ketersedian Air Radiator Pada Mobil. Palembang: Politeknik Negeri Sriwijaya. 